\title{
Preliminary phytochemical screening of Quercus infectoria Oliv. for treatment of skin diseases
}

\author{
Vaibhav Vaidya $^{1 \star}$, C. B. Mahendrakumar ${ }^{2}$ and Kiran Bhise ${ }^{3}$ \\ ${ }^{1}$ Pad. Dr. D.Y. Patil College of Pharmacy, Akurdi, Pune Maharashtra- 411044 , India. \\ ${ }^{2}$ St. Marry College of Pharmacy, Secunderabad Andhra Pradesh- 500 025, India. \\ ${ }^{3}$ MCE Socy's Allana College of Pharmacy, Camp, Pune Maharashtra- 411 001, India.
}

Accepted 3 July, 2013

\begin{abstract}
In present work, fruits of Quercus infectoria are selected on the basis of traditional claim. Fingerprinting analysis for the said extract along with the biomarker, gallic acid was performed using high performance thin layer chromatography (HPTLC). The extract and biomarker were standardized with various instrumental techniques like Newton magnetic resonance (NMR), Fourier transform infrared (FTIR) and ultraviolet (UV) spectroscopies. Preliminary phytochemical screening was performed for establishing the profile of extract for its nature of chemical composition. The extracts showed the presence of tannins, mucilage and saponins. HPTLC fingerprinting showed better separation of the components. Planer chromatogram generated was used to determine existence of present phytoconstituents. The $R_{f}$ value was found to be 0.19 . The extract exhibited good correlation with selected marker in different analytical techniques like NMR, FTIR and UV spectroscopies. UVSpectroscopic analysis showed good correlation between plant extract and standard (gallic acid). The extract and biomarker exhibited $0.074,0.0511$ and $0.003,0.0429$ intercept and slope values, respectively.
\end{abstract}

Key words: Quercus infectoria, gallic acid, high performance thin layer chromatography (HPTLC), Newton magnetic resonance (NMR), Fourier transform infrared (FTIR), ultraviolet (UV) spectroscopy, tannins.

\section{INTRODUCTION}

The ancient literature of Ayurveda has served the wellbeing of mankind because of empirical knowledge of the observations and the experience of Ayurveda practitioner. Though traditional medicines offer a safe and inexpensive approach to treat many skin diseases, it has been neglected due to some reasons like shortcoming in treating chronic condition and unavailability of pathological data (Govindarajan, 2007; Al-Quran, 2008).

In this work, fruits of Quercus infectoria Oliv. (Fagaceae) which is also traditionally known as Majuphal was selected on the basis of traditional claim (Khouzami, 2009; Kaur, 2008). The reported constituents of plant are tannins, saponins and mucilage. This study has been focused on phytochemical investigation of $Q$. infectoria which has been reported as potent candidate for treating skin diseases and inflammatory conditions (Umachigia, 2008; Leela, 2011). The existence of the aforementioned phytoconstituents is determined using proximate analysis, fingerprinting analysis of extract and biomarker using high performance thin layer chromatography (HPTLC) and other instrumental techniques like Newton magnetic resonance (NMR), Fourier transform infrared (FTIR) and ultraviolet (UV) spectroscopies.

\section{MATERIALS AND METHODS}

Plant collection and extraction

The fresh fruits of $Q$. infectoria were selected for this study. Selected plant was collected from Pune region and authenticated 


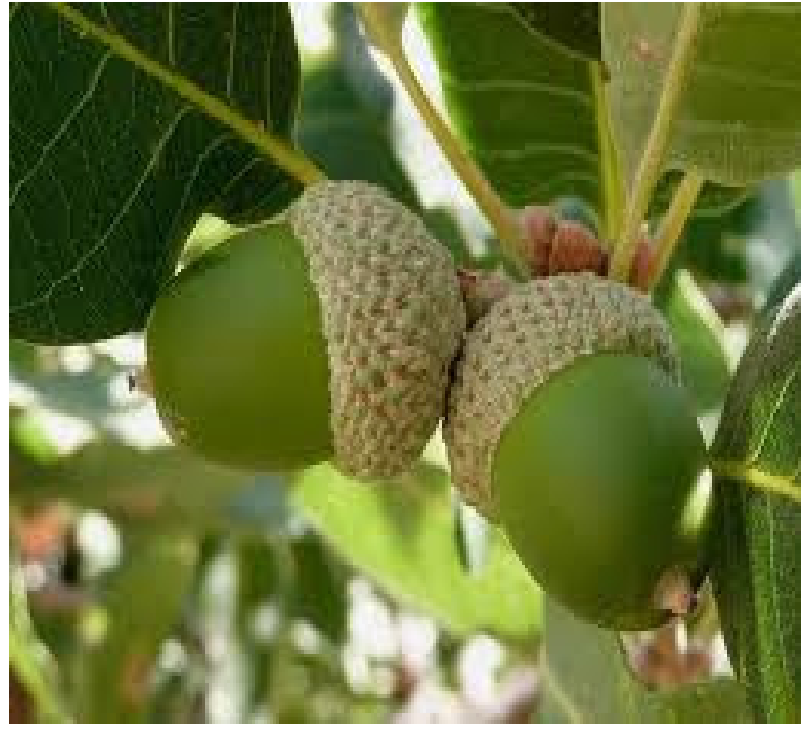

Figure 1. Fruits of $Q$. infectoria.

from Department of Botany, University of Pune, Maharashtra, India (Voucher No. Bot/34/2010) (Figure 1). Proximate analysis of powder was carried out for different physicochemical standards such as ash values, extractive values and loss on drying (Mukherjee, 2002).

The hydroalcoholic extracts in the proportion 60:40 for the selected herbal plant was prepared by simple maceration for about $72 \mathrm{~h}$ and concentrated and stored in air tight container (Chusri, 2009; Vermani, 2010).

\section{Phytochemical analysis}

The crude extract was subjected to preliminary phytochemical screening for the detection of various phytoconstituents (Ghafour, 2010; Wallis, 1985).

\section{Histology}

The plant specimen for the study was cut and fixed in formalin acetic acid (FAA) and was dehydrated (Sass, 1940). Infiltration was carried out by addition of paraffin wax and this paraffin embedded specimens were sectioned with the help of rotary microtone. The sections were stained with Toluidine blue and observed under microscope (O'Brien et al., 1964). Photographs of different magnifications were taken with Nikon Laboratory Photo 2 Microscopic Unit with the help of plane polarized light for the study of various organs (Esau, 1964).

\section{Fingerprinting and spectroscopic analysis}

The crude extract of selected plant was analyzed for HPTLC fingerprinting using Camag HPTLC system equipped with an automatic TLC sampler and TLC scanner with a UV cabinet. Planer chromatograms of samples prepared using general solvent system Toulene:Chloroform:Ethanol (8:8:2) and solution prepared as 100 $\mathrm{mg}$ in $5 \mathrm{ml}$ of methanol. UV-Spectroscopic analysis of extract and biomarker was performed using Shimadzu 1700 UV spectrophotometer. NMR as well as FTIR investigation was performed on extract and biomarker (Jamil, 2012; Rodriguez, 2008; Carmen, 2008).
Table 1. Preliminary Phytochemical Screening of $Q$. infectoria.

\begin{tabular}{clc}
\hline S/N & Nature of constituent & Sample (Q. infectoria) \\
\hline 1 & Alkaloids & - \\
2 & Carbohydrates & + \\
3 & Flavonoids & - \\
4 & Glycosides & - \\
5 & Lipids & + \\
6 & Mucilage & + \\
7 & Phytosterols & - \\
8 & Proteins and amino & - \\
9 & Sapids & + \\
10 & Tannins & + \\
11 & Volatile oils & - \\
\hline
\end{tabular}

\section{RESULTS}

\section{Pharmacognostic study}

The various physicochemical standards such as ash values, extractive values and loss on drying was performed. Preliminary phytochemical screening was performed for establishing the profile of extract for its nature of chemical composition (Soon et al., 2007; Aroonrerk, 2009).

\section{Phytochemical analysis}

Preliminary phytochemical screening was performed for establishing the profile of extract for its nature of chemical composition. The extracts showed the presence of tannins, mucilage and saponins. The results are listed in Table 1.

\section{Histology}

It shows the pericarp of around $250 \mu \mathrm{m}$ thick and consist of thin walled parechymatous cells somewhat radialy oblong and possess dense accumulation of tannins. Mesocarp shows thin layers of parenchyma with the vascular strands including masses of fibers, xylem and phloem. The endocarp shows columnar sclerides. The cotyledon is seen in parallel longitudinal sections. It is bilobed and embryo is placed in wide longitudinal cylindrical chamber (Figures 2 to 4 ).

\section{Fingerprinting and spectroscopic analysis}

HPTLC fingerprinting showed better separation of the components. Planer chromatogram generated was used to determine existence of present phytoconstituents. The $R_{f}$ value was found to be 0.19 (Graph 1 and Figure 5). 


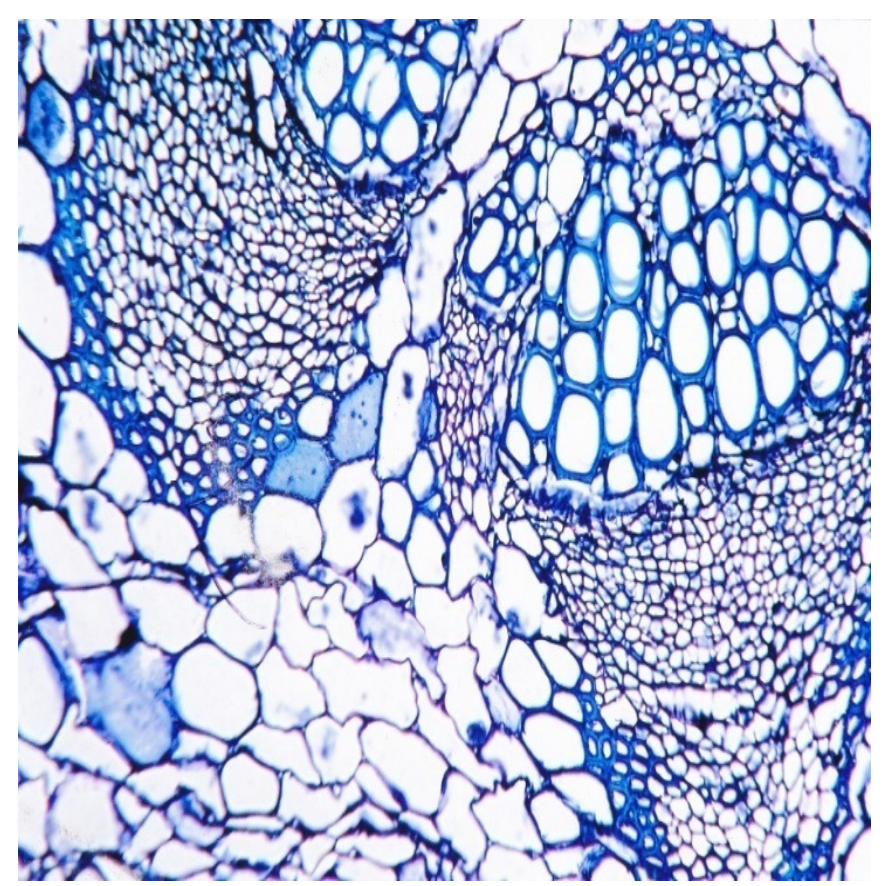

Figure 2. Histology showing the pericarp region.

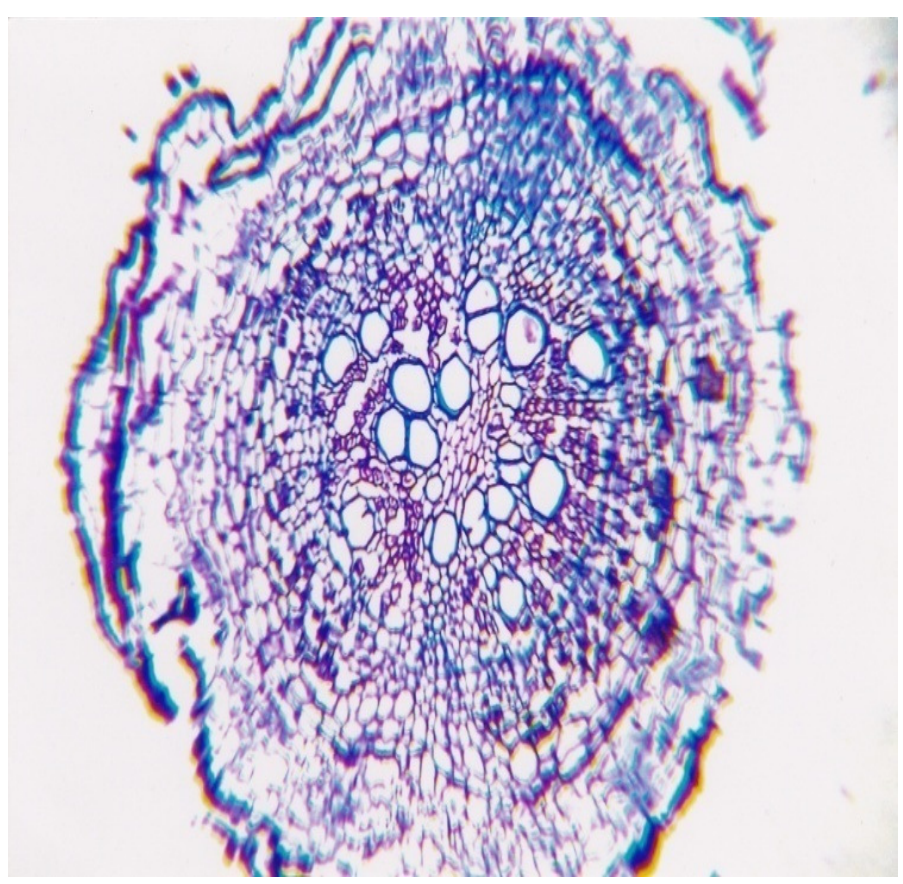

Figure 3. Entire section of fruit.

UV calibration curve was plotted for plant extract as well as biomarker, gallic acid at 275 and $260 \mathrm{~nm}$, respectively. UV-Spectroscopic analysis showed good correlation between plant extract and standard (gallic acid).
Table 2. Calibration of Quercus infectoria at $275 \mathrm{~nm}$.

\begin{tabular}{cc}
\hline Concentrations $(\mathbf{m c g} / \mathbf{m l})$ & Absorbances \\
\hline 0 & 0 \\
15 & 0.407 \\
30 & 0.798 \\
60 & 1.568 \\
90 & 2.161 \\
120 & 2.763 \\
\hline
\end{tabular}

Table 3. Calibration curve of gallic acid at $260 \mathrm{~nm}$.

\begin{tabular}{cc}
\hline Concentrations $(\mathbf{m c g} / \mathbf{m l})$ & Absorbances \\
\hline 0 & 0 \\
2 & 0.101 \\
4 & 0.215 \\
6 & 0.313 \\
8 & 0.399 \\
10 & 0.51 \\
\hline
\end{tabular}

The extract and biomarker exhibited $0.074,0.0511$ and $0.003,0.0429$ intercept and slope values, respectively (Tables 2 and 3; Graphs 2 and 3). UV-Spectroscopic analysis showed good correlation between plant extract and standard (gallic acid). FTIR and NMR spectra were run for extract and biomarker. The extract and marker showed good correlation in FTIR.

Extract showed prominant peak values at 2364.81, 2148.77 and $1915.38 \mathrm{~cm}^{-1}$ whereas gallic acid showed peak at $2048.47 \mathrm{~cm}^{-1}$ (Graphs 4 and 5). Similarly, NMR also exhibited good correlation for sample and biomarker (Graphs 6 to 9).

\section{DISCUSSION}

Thus in recent years there is spurt in the interest regarding survival of Ayurvedic forms of medication due to shorcomings of modern medicines. Tannins serves as natural defense mechanism against microbial infections can also be used in some inflammatory conditions (Abdul, 2005; Adel, 2010). Phytochemical analysis of hydroalcoholic extract of fruits of $Q$. infectoria showed the presence of tannins (Basri, 2004) which is confirmed by fingerprinting and spectroscopic analysis. The study can be further extended in formulation of this potent candidate for treatment of skin diseases as tannins act as free radical scavengers as well as antimicrobial agents. 


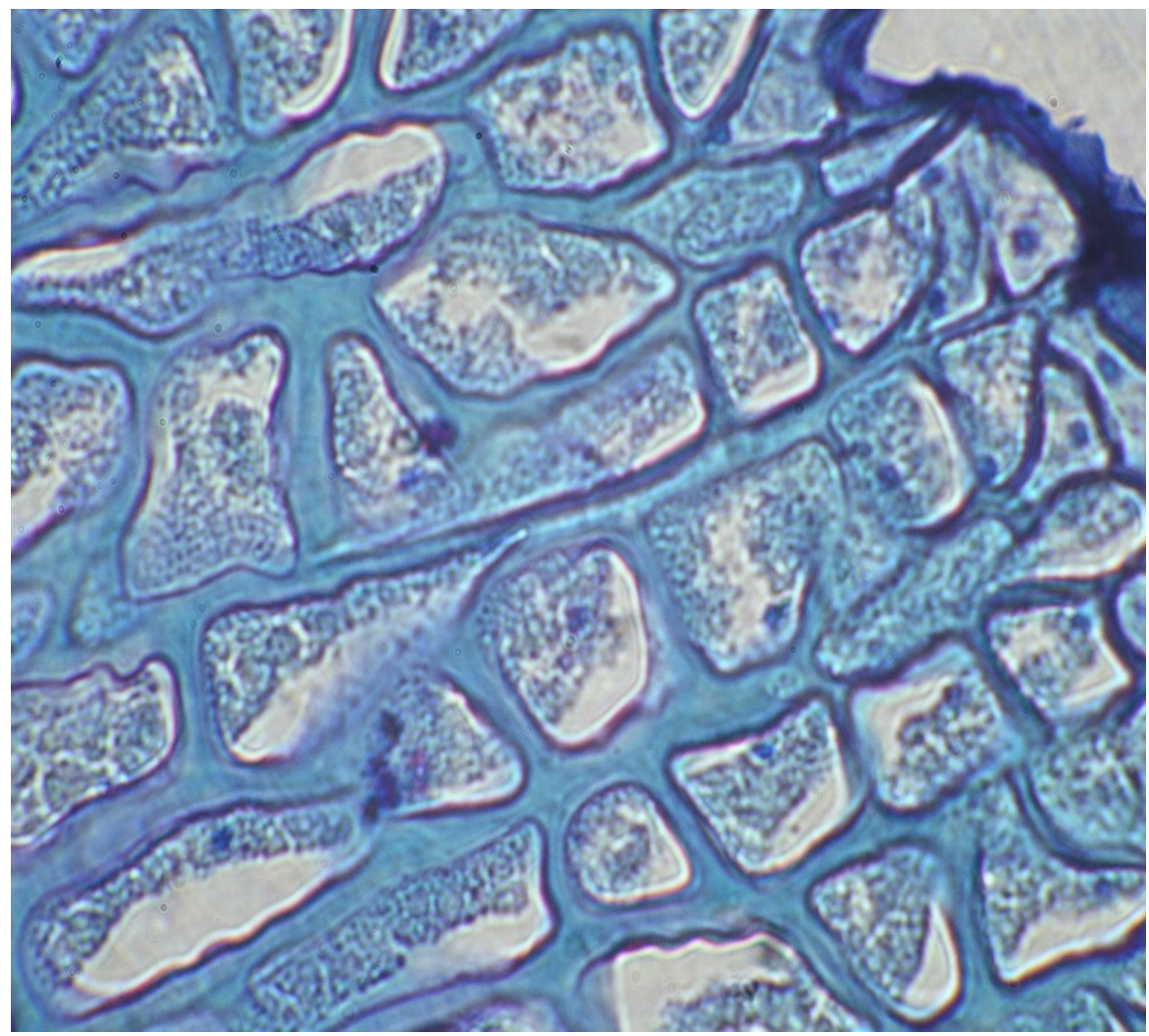

Figure 4. Endocarp showing colomnar sclerides.
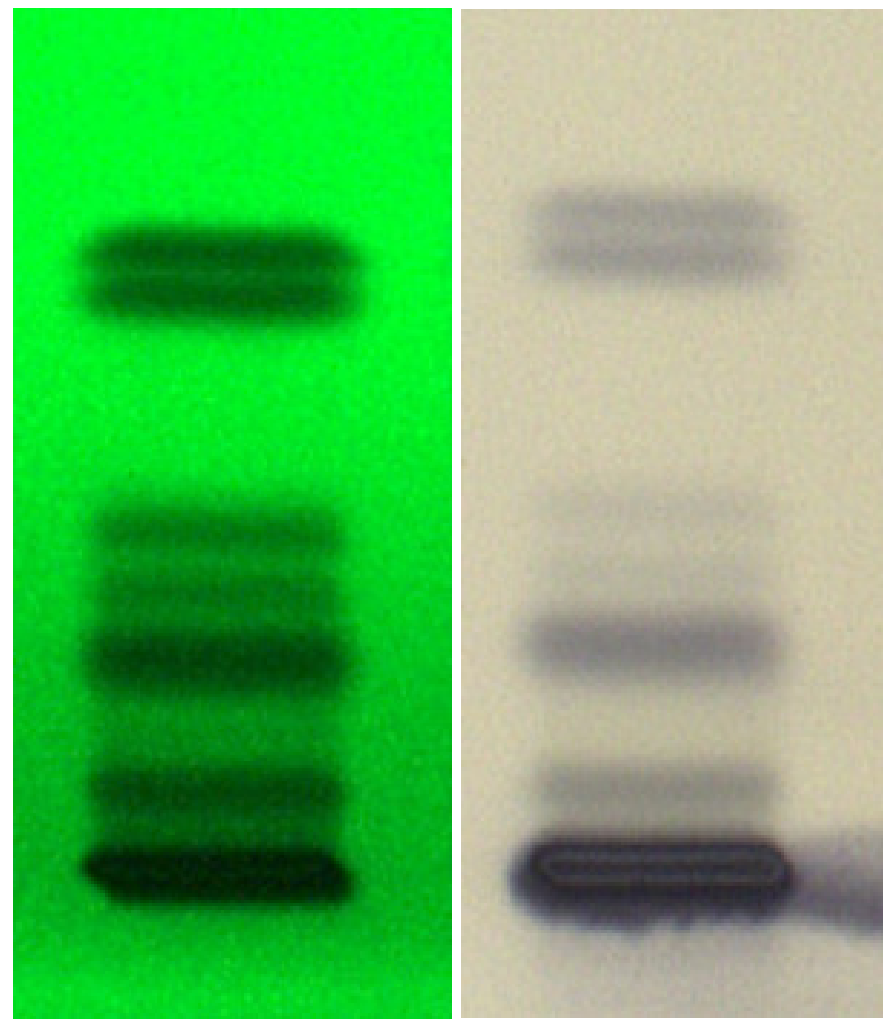

Figure 5. HPTLC band of $Q$. infectoria 
| Track 2, ID: Q.infectoria
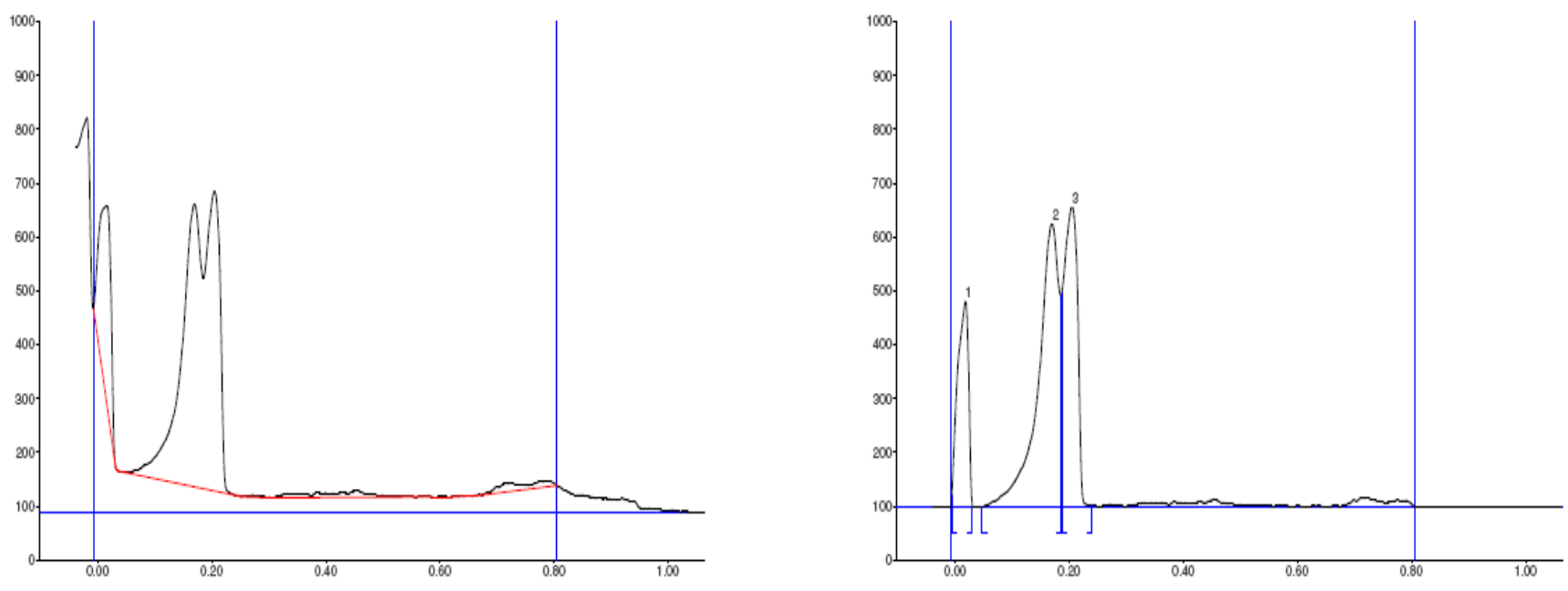

\begin{tabular}{|c|c|c|c|c|c|c|c|c|c|c|}
\hline & Start & Start & Max & Max & Max & End & End & & rea & \\
\hline Peak & Rf & Height & $\mathrm{Rf}$ & Height & $\%$ & $\mathrm{Rf}$ & Height & Area & $\%$ & Assigned subste \\
\hline 1 & -0.01 & 21.1 & 0.02 & 381.1 & 26.04 & 0.03 & 0.7 & 6531.3 & 18.24 & unknown * \\
\hline 2 & 0.05 & 0.3 & 0.17 & 525.5 & 35.91 & 0.19 & 391.9 & 17275.5 & 48.25 & unknown * \\
\hline 3 & 0.19 & 396.2 & 0.21 & 556.8 & 38.05 & 0.24 & 1.0 & 12000.5 & 33.51 & known * \\
\hline
\end{tabular}

Graph 1. Planer Chromatogram of Quercus infectoria.

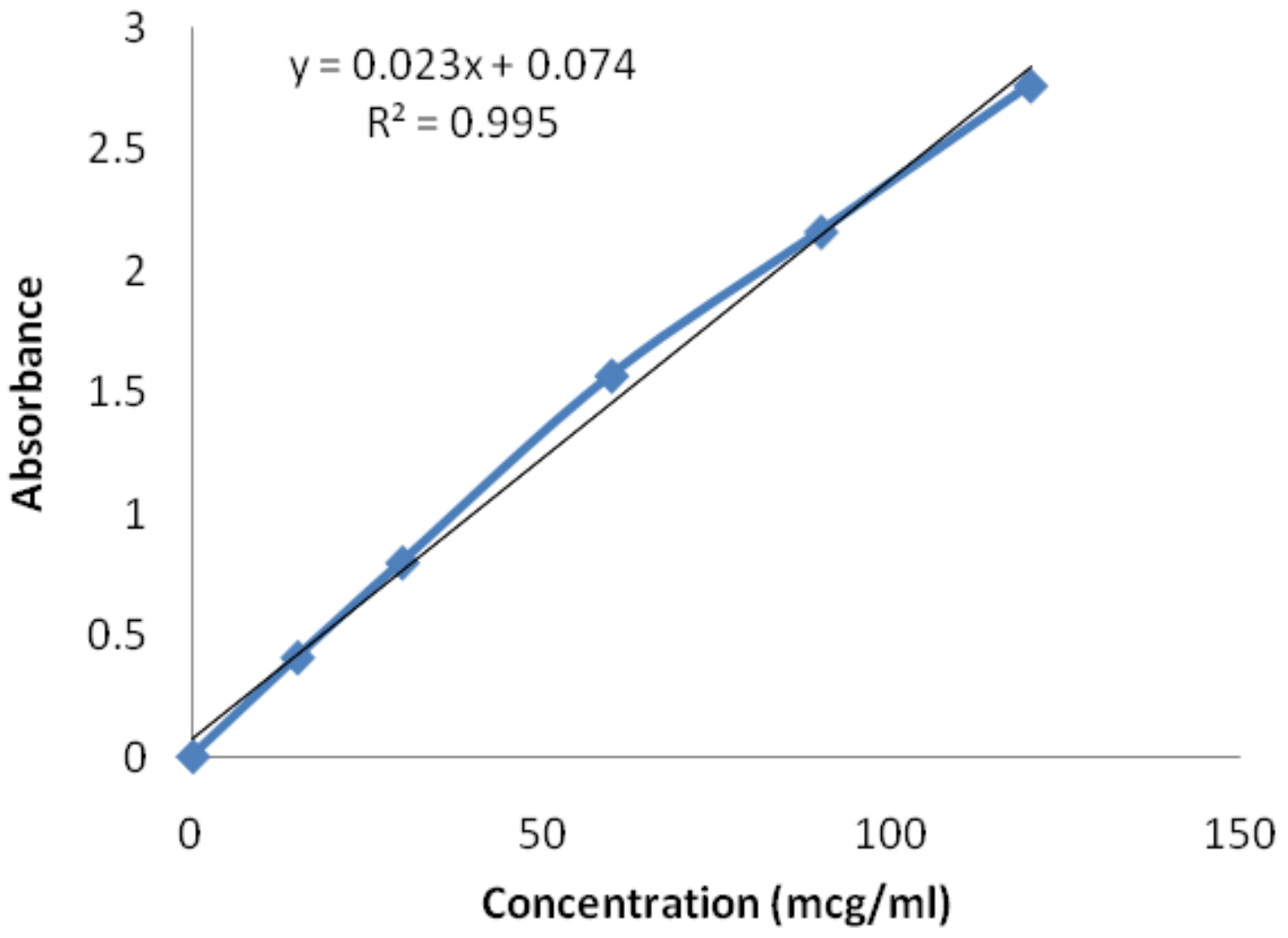

Graph 2. Calibration Curve of Quercus infectoria at $275 \mathrm{~nm}$. 


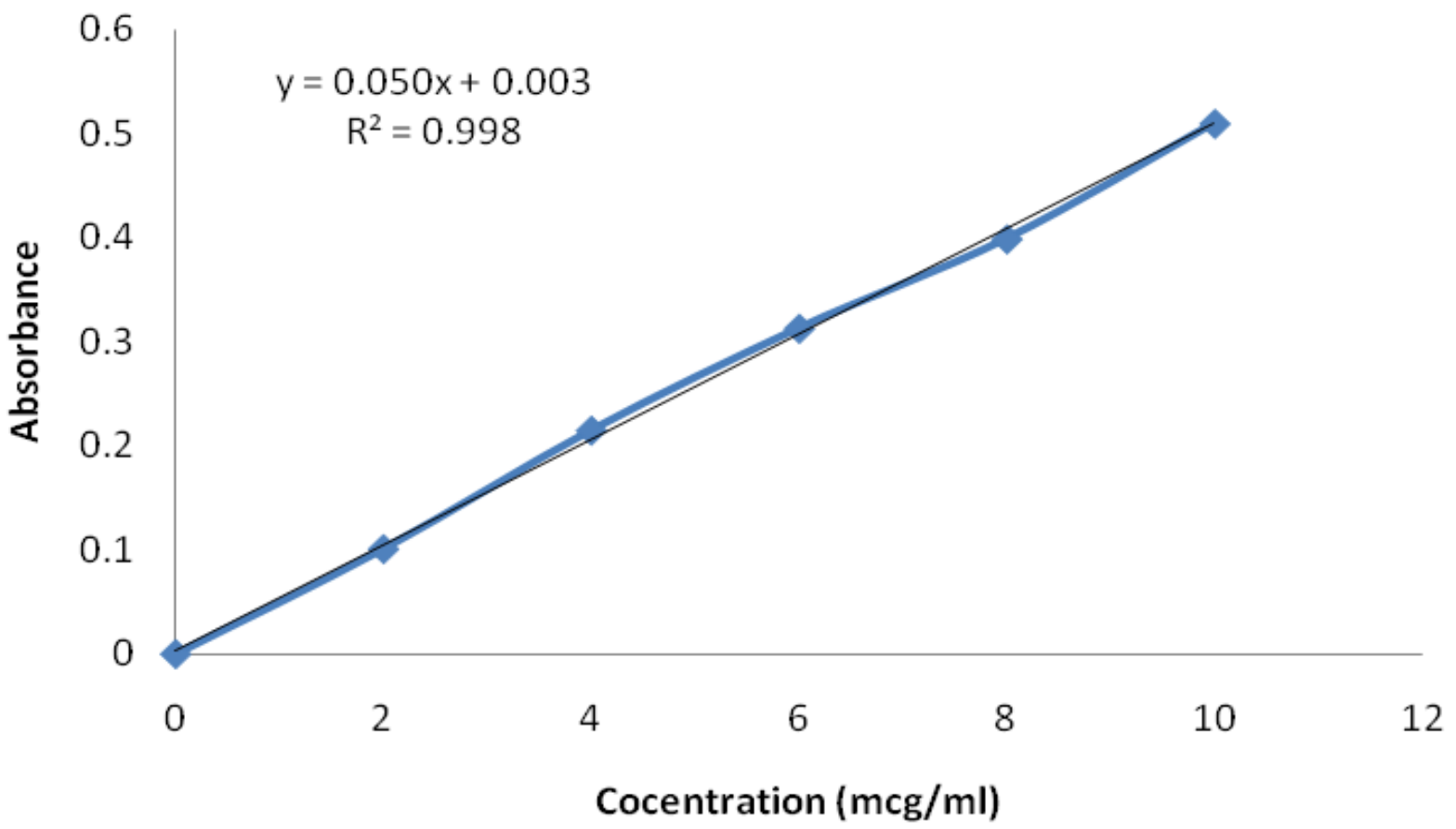

Graph 3. Calibration curve of gallic acid at $260 \mathrm{~nm}$.

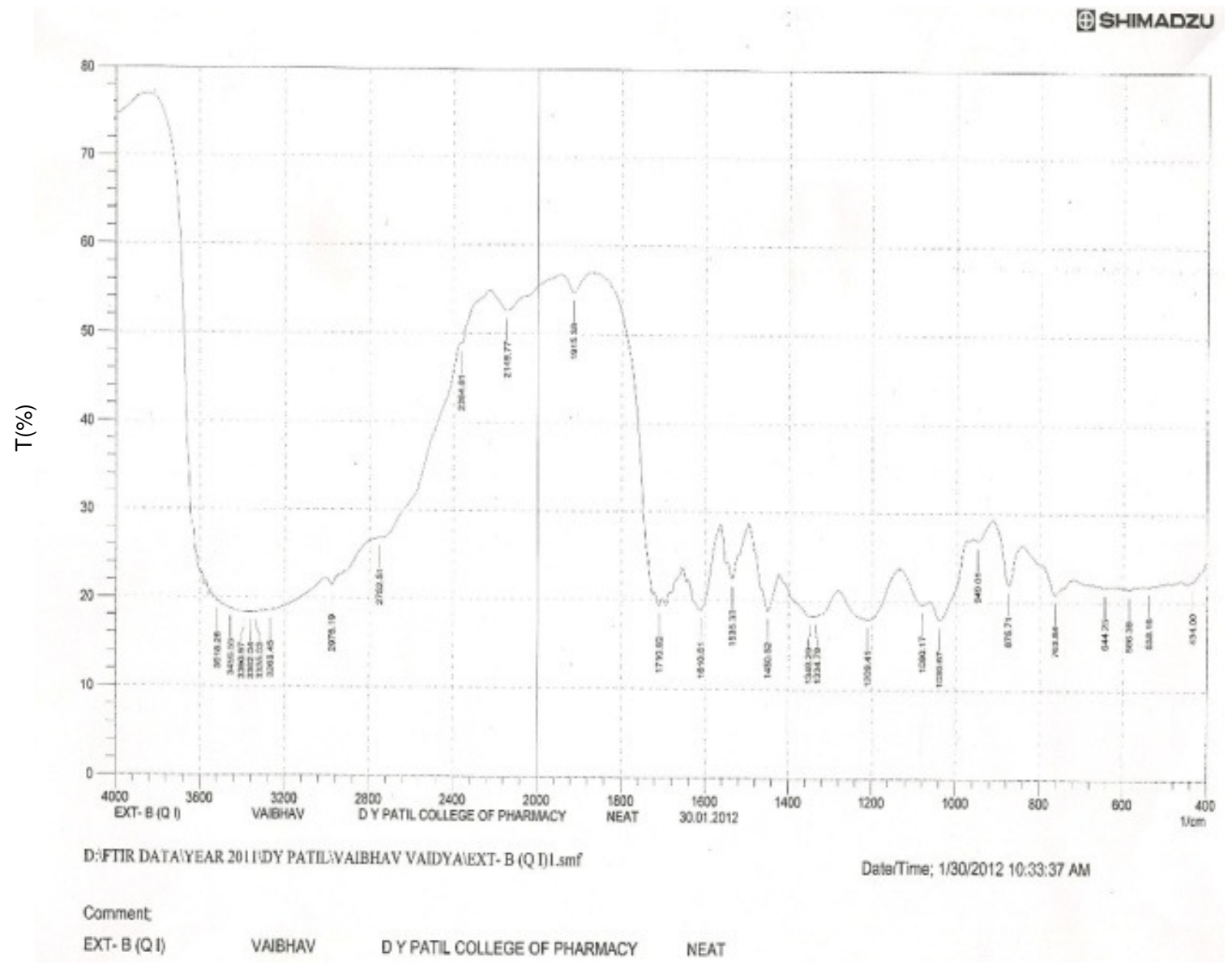

Graph 4. FTIR Spectra of Q. infectoria. 




Comment:

GALIC ACID STD VAIBHAV DY PATIL COLLEGE OF PHARMACY KBR

Graph 5. FTIR Spectra of Biomarker (Gallic acid).

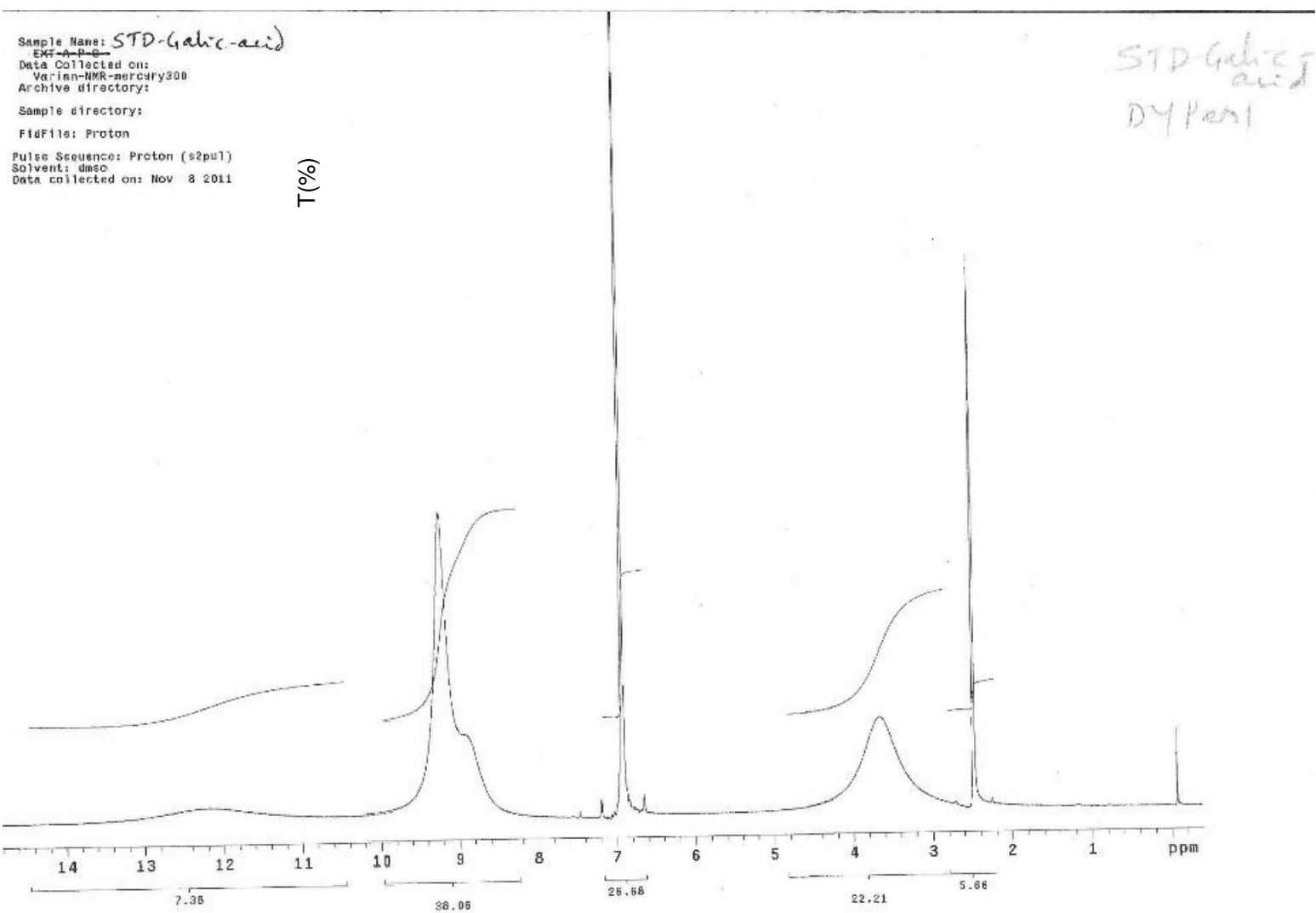

Graph 6. $\mathrm{H}^{1} \mathrm{NMR}$ of gallic acid. 

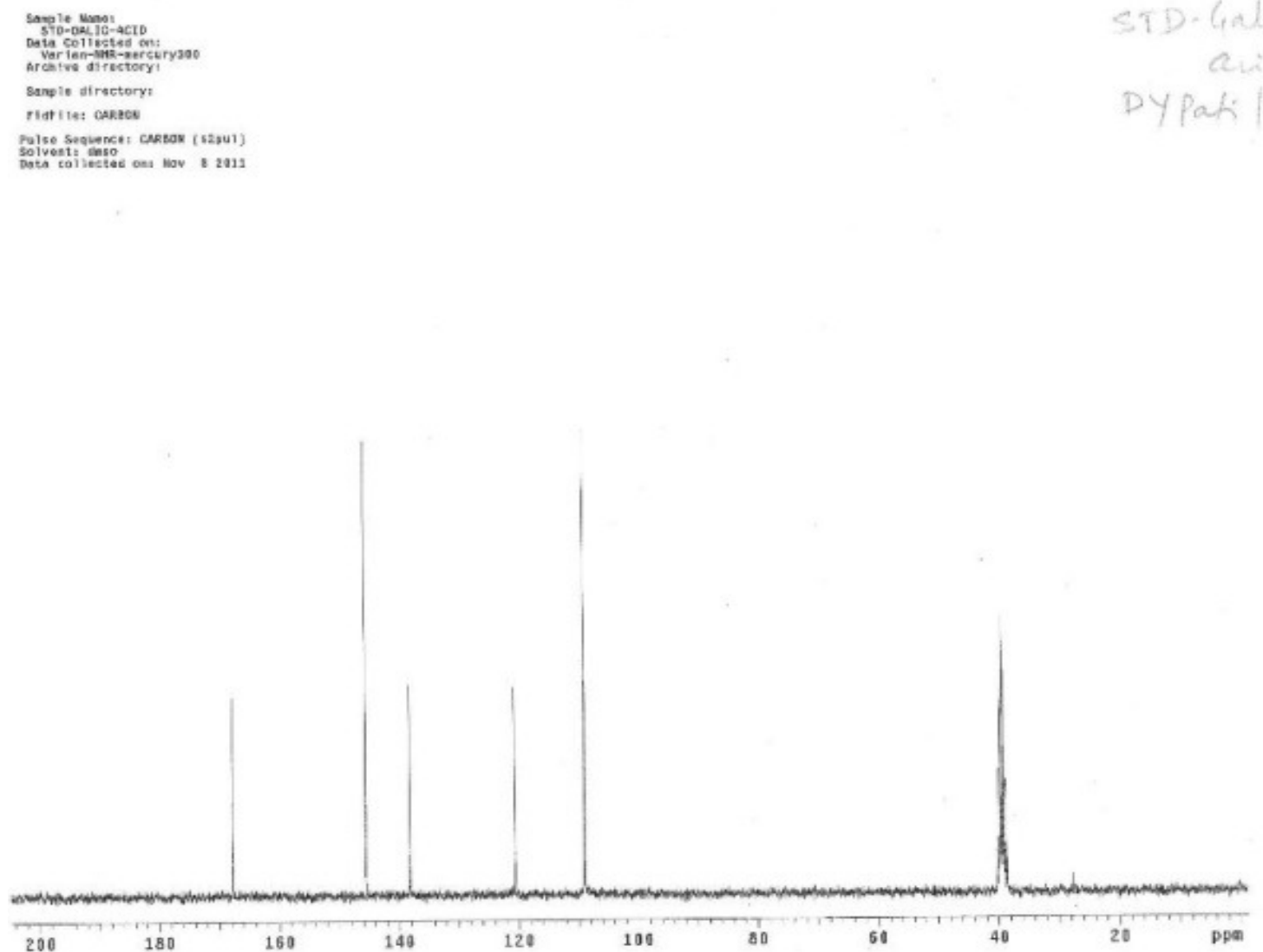

Graph 7. Carbon NMR of Gallic acid.

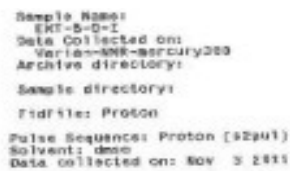

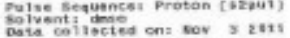

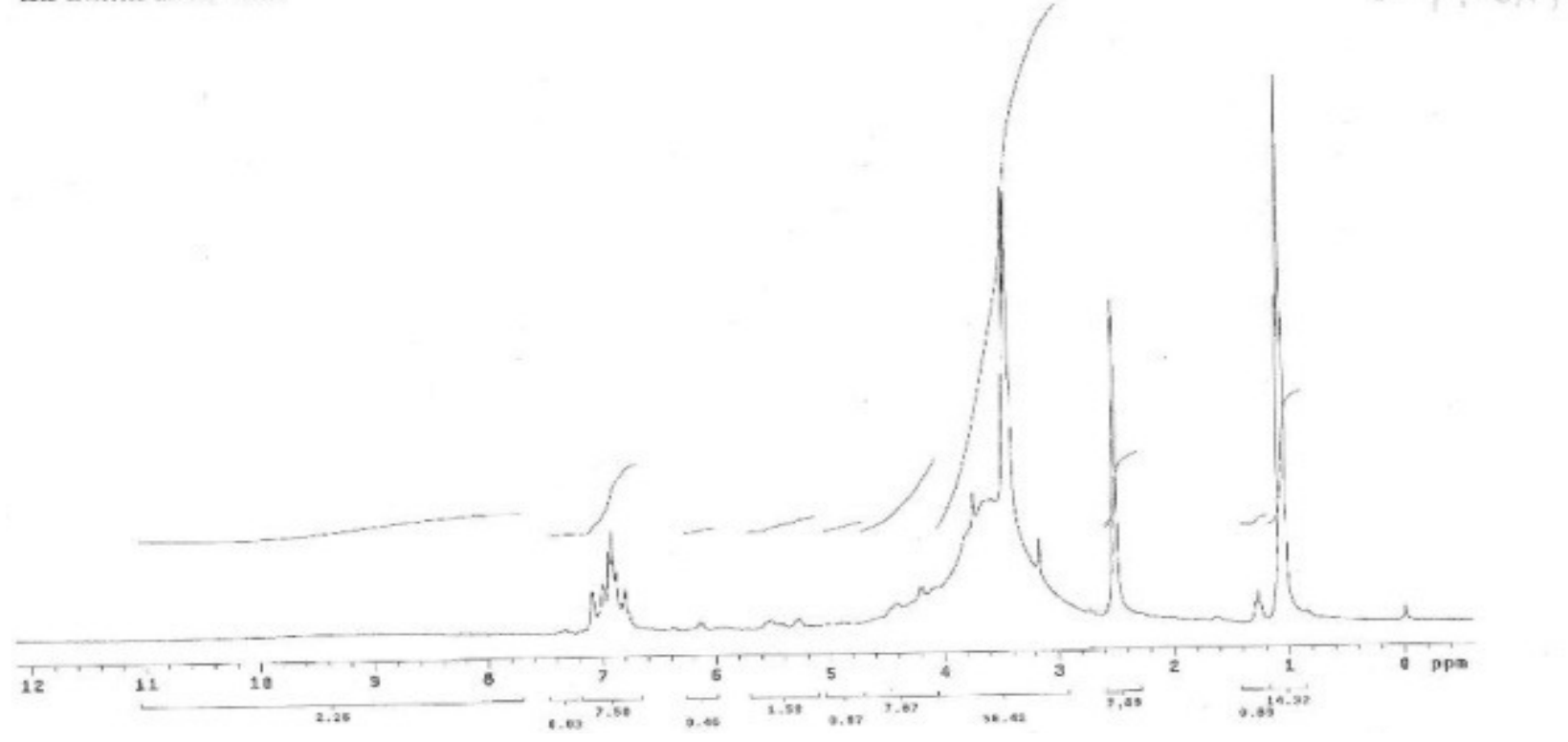

Graph 8. NMR of $Q$. infectoria. 

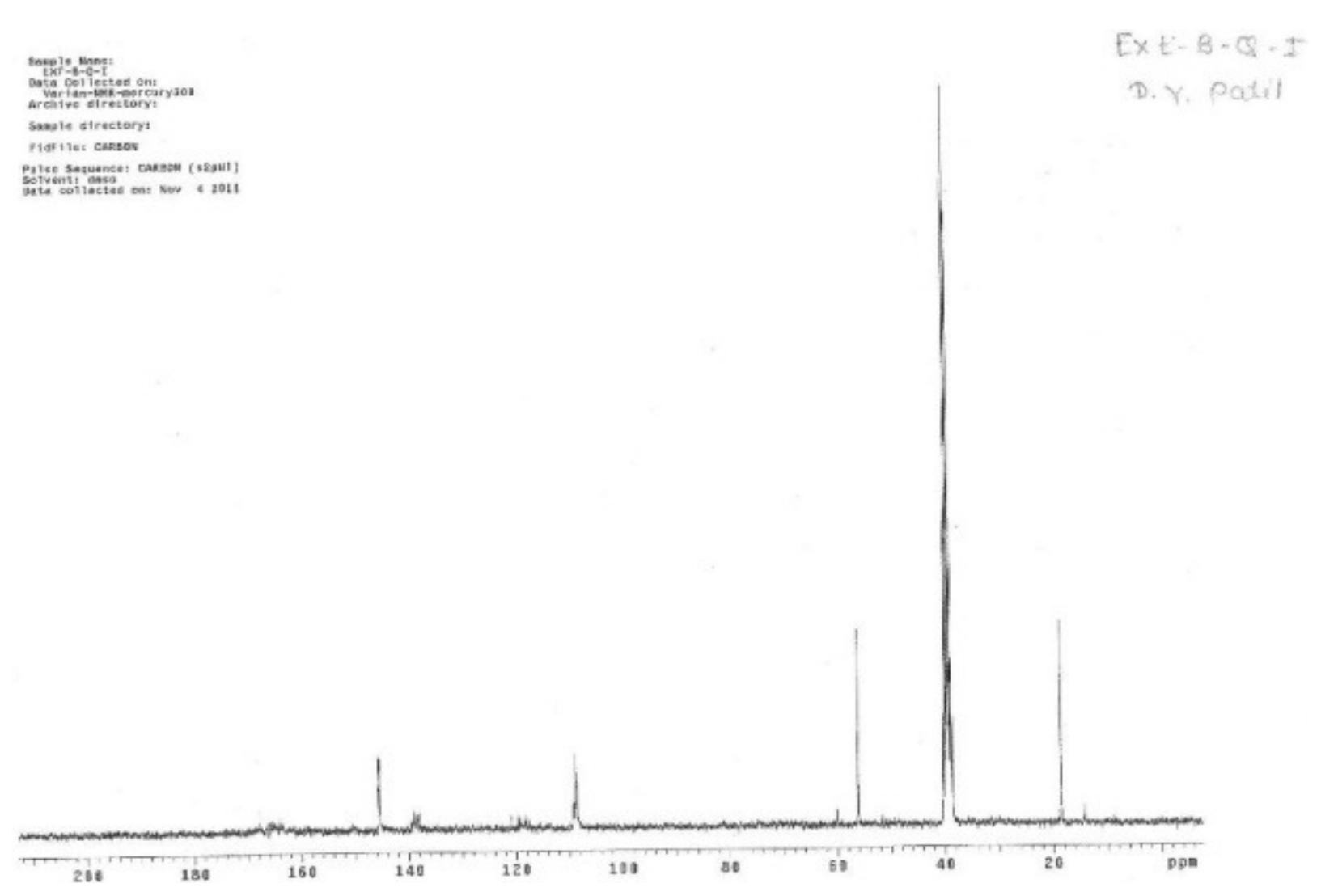

Graph 9. Carbon NMR of $Q$. infectoria.

\section{REFERENCES}

Abdul-Aziz JRM (2005). The potential of aqueous and acetone extracts of galls of Quercus infectoria as antibacterial agent. Indian J. Pharmacol. 37(1):26-29.

Adel KK, Muhammed SA (2010). Potential of Aqueous and Alcohol Extracts of Quercus infectoria, Linusm usitatissium and Cinnamomum zeylanicium as Antimicrobials and Curing of Antibiotic Resistance in E. coli. Cur. Res. J. Biol. Sci. 2(5):333-337.

Al-Quran S (2008). Taxonomical and Pharmacological Survey of Therapeutic Plants in Jordan. J. Nat. Prod. 1:10-26.

Aroonrerk N, Kamkaen N (2009). Anti-inflammatory activity of Quercus infectoria, Glycyrrhiza uralensis, kaempferia galanga and Coptis chinensis, the main components of Thai herbal Remedies for aphthous ulcer. J. Health Res. 23(1):17-22.

Basri DF, Fan SH (2004). The potential of aqueous and acetone extracts of galls of Quercus infectoria as antibacterial agents. Indian J. Pharmacol. 37(1):26-29.

Carmen GC, Héctor R, Blanca R, Rosario M (2008). Degradation of tannic acid by cell-free extracts of Lactobacillus plantarum. Food Chem. 107(2):664-670.

Chusri S, Voravuthikunchai SP (2009). Detailed studies on Quercus infectoria Olivier (nutgalls) as an alternative treatment for methicillinresistant Staphylococcus aureus infections. J. Appl. Microbiol. 106: 89-96.

Esau K (1964). In: Plant Anatomy. John Wiley and Sons. New York, p 767.

Ghafour N, Hoshyar AA, Raad MA (2010). Determination of Some Chemical Constitutes of Oak Plants (Quercus spp) in the Mountain Oak Forest of Sulaimani Governorate. J. Zankoy Sulaimani 13(1):129-142.

Kaur G, Athar M, Alam MS (2008). Quercus infectoria galls possess antioxidant activity and abrogates oxidative stress-induced functional alterations in murine macrophages. Chem. Biol. Interact. 171(3):272282.

Khouzami L, Mroueh M, Daher FC (2009). The role of methanolic extract of Quercus infectoria bark in lipemia, glycemia, gastric ulcer and bacterial Growth. J. Med. Plants Res. 2(4):224-230.

Kumar B, Vijayakumar M, Govindarajan R, Pushpangadan P (2007). Ethnopharmacological Approaches to wound healing-exploring medicinal plants of India. J. Ethnopharmacol. 114(2):103-113.

Leela T, Satirapipathkul C (2011). Studies on the Antibacterial Activity of Quercus Infectoria Galls. Int. Proceed. Chem. Biol. Environ. Engine. 5:410-414.

Jamil M, Ihsan H, Mirza B, Qayyum M (2012). Isolation of Antibacterial compounds from Quecus dilatata L. through bioassay guided fractionation. Ann. Clin. Microbiol. Antimicrob. 11:11.

Mukherjee PK (2002). In: Quality Control on Herbal Drugs. Eastern Publishers (Business Horizons Ltd.) New Delhi, p. 212.

O'Brien TP, Feder N, Mc Cull ME (1964). Polychromatic staining of Plant Cell walls by toluidine blue. O Protoplasma. 59:364-373.

Sass JE (1940). In: Elements of Botanical microtechnique. McGraw Hill Book co. New York. p 222.

Soon LK, Hasni E, Law KS, Waliuttah SS, Farid GG, Syed MSS (2007). Ultrastructural Findings and Elemental Analysis of Quercus infectoria Oliv. Ann. Microscopy 7:32-37.

Umachigia SP, Jayaveera KN, Ashok KCK, Kumar GS, Vrushabendra SBM, Kishore KDV (2008). Studies on Wound Healing Properties of Quercus infectoria. Trop. J. Pharm. Res. 7(1): 913-919.

Vermani A, Navneet P, Chauhan A (2010). Physico-Chemical Analysis of Ash of Some Medicinal Plants Growing in Uttarakhand, India. Nat. Sci. 8(6):88-91.

Wallis TE (1985). In: Text Book of Pharmacognosy. CBS Publishers and Distributors. Delhi, pp. 101-102. 